\title{
Evaluation the efficacy of educational booklet of oral diseases on the patients' knowledge referred to Mashhad Dental School in 2016, Iran
}

\author{
P. Mosannen Mozaffari ${ }^{1}$, A .Ghazi ${ }^{1}$, M. Amirchaghmaghi ${ }^{1}$, Z. Khojasteh Galayemi ${ }^{2}$
}

\author{
${ }^{1}$ Oral and Maxillofacial Diseases Research Center, Mashhad University of Medical Sciences, Mashhad, Iran \\ ${ }^{2}$ Dentist, Mashhad, Iran \\ Corresponding Address: Maryam Amirchaghmaghi, Dental School, Azadi Square, Vakilabad Blvd., Mashhad, \\ Iran \\ Tel: +98-51-38829501; Email: amirchakhmaghim@mums.ac.ir \\ Received: 18 Apr 2018; Accepted: 22 Sep 2018
}

\section{Abstract}

Background: Due to the high prevalence of oral diseases and lack of knowledge, giving the proper education is needed to familiarize patients with oral diseases.

Objective: This study aimed to determine the efficacy of using an educational booklet on patients knowledge.

Methods: This interventional study was conducted from spring to winter 2016 on fifty patients referred to Mashhad Dental School. An educational booklet of oral diseases describes various domains of oral diseases in six different groups. Also a questionnaire containing 18 questions of oral diseases that was prepared and used in two stages, prior to the intervention and after the intervention. The patients were divided into control $(n=25)$ and intervention $(n=25)$ groups. Initially, a pre-test questionnaire was given to both groups. The intervention group received the educational booklet. After one month, the post-test questionnaire was taken from both groups. Chi-square, Mann-Whitney, Fisher and independent t-test were used for statistical analysis.

Findings: The difference between mean score changes was significant in both groups respectively 1.6 \pm 0.12 and $5.4 \pm 1.5(\mathrm{P}<0.001)$. The intervention significantly increased the knowledge score for all domains in the intervention group compared to the control group $(\mathrm{P}<0.001)$. The booklet had the most significant effect on the awareness of cancer and the least influence on pain.

Conclusion: It seems that the educational booklet significantly could enhance the level of patients' knowledge about oral diseases.

Keywords: Booklet, Mouth diseases, Oral cancer, Patient medication knowledge

Citation: Mosannen Mozaffari P, Ghazi A, Amirchaghmaghi M, Khojasteh Galayemi Z, Javan Rashid A. Evaluation the efficacy of educational booklet of oral diseases on the patients' knowledge referred to Mashhad Dental School in 2016, Iran. J Qazvin Univ Med Sci 2018; 22(4): 31-39. 


\title{
بررسى ميزان اثربخشى كتابِه آموزشى بيمارىهاى شايع دهان در بيماران مراجعه كننده به

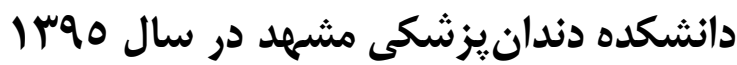

\author{
دكتر يحاه مسنن مظفرى'، دكتر آلا قاضى'، دكتر مريم اميرجقماقى'، دكتر زهرا خجسته كَلايمى'
}

' مركز تحقيقات بيمارى هاى دهان، فكى و صورت دانشكاه علوم يزشكى مشهل، مشهد، ايران r مندانيز شك، مشهل، ايران

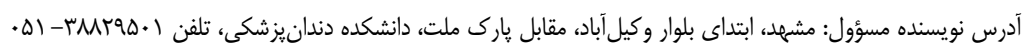

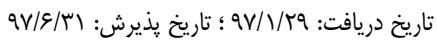

زمينه: با توجه به شيوع بالاى بيمارىهاى دهان و كمبود دانش در اين زمينه، به آموزشى صحيح جهت آشنايى بيماران با بيمارىهـاى دهـان نيـاز

است.

هدف: اين مطالعه با هدف تعيين تأثير استفاده از كتابهه آموزشى بر ميزان افزايش دانش بيماران طراحى كَرديد.

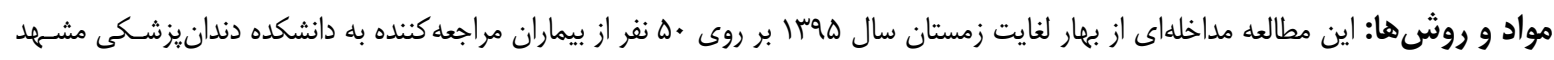

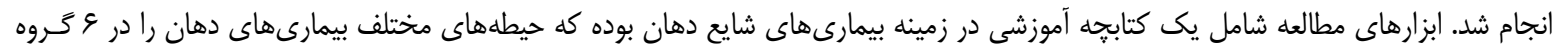

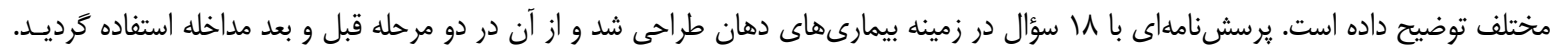

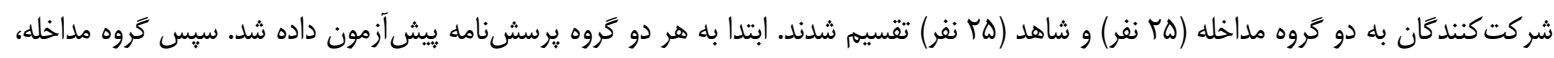

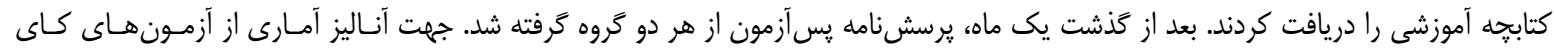

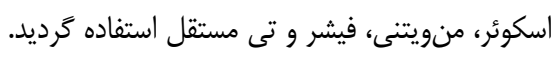

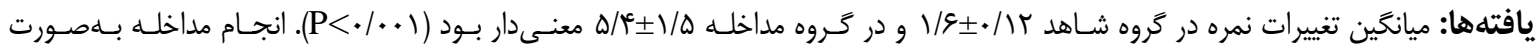

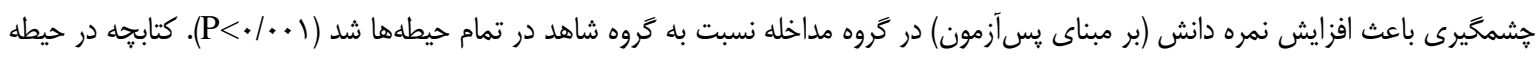

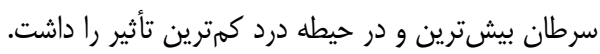

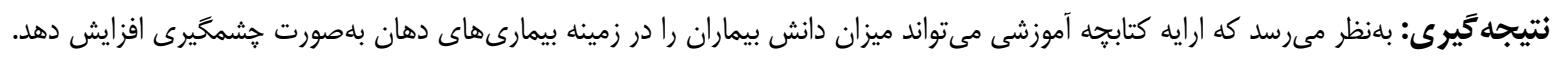

كليدوازهها: كتابحه، بيمارىهاى دهان، سرطان دهان، دانش يزشكى بيمار

ميزان شيوع بيمارى يريودنتال، سرطان دهان و يوسيدگى

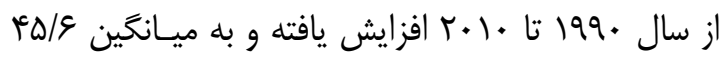

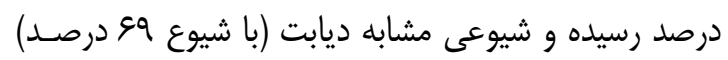

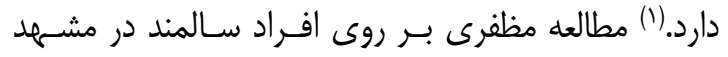

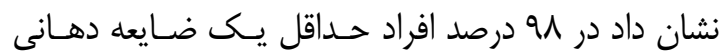

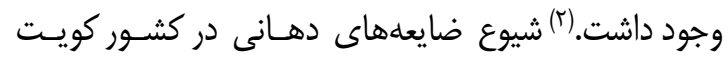

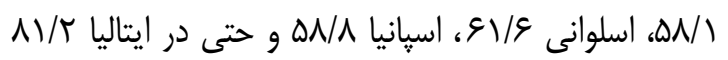

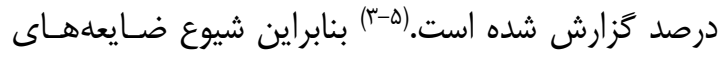

(مقدمه:

حفره دهان در توانايى خوردن، جويدن، بلـع، صـبت

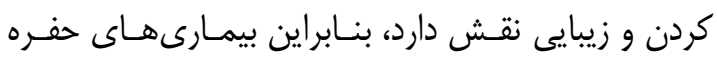

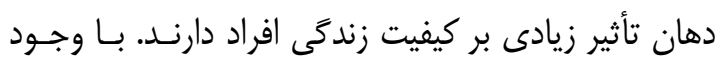

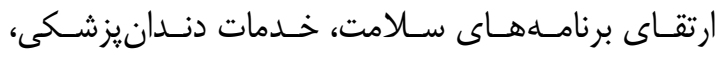
دانشكدهها و درمانكاههاى دندانيز شكى و افـزايش تعـــاد

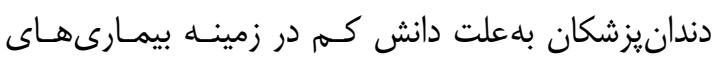

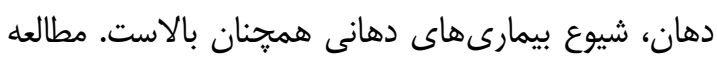

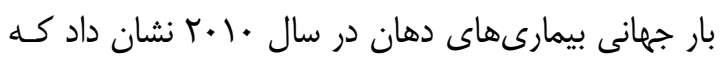


را منتقل مى كند و مخاطب مىتواند بارها و بارها اطلاعات

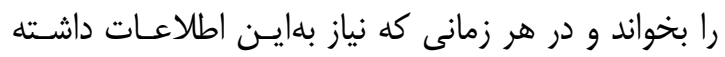

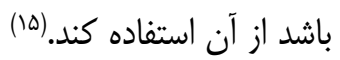

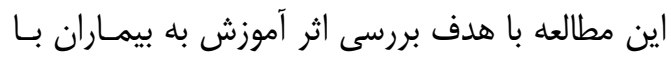
استفاده از كتابِه راهنماى بيمارى إنهاى شايع حفره دهـان در دانشكده دندانيزشكى مشهد انجام شد.

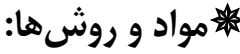

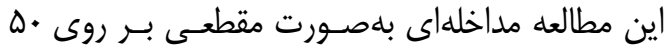

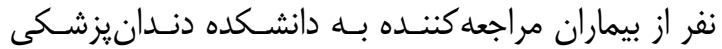

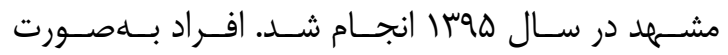

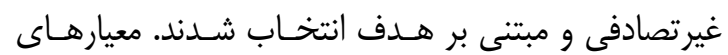

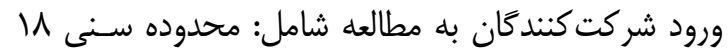

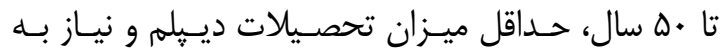

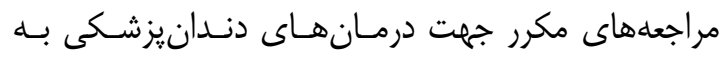

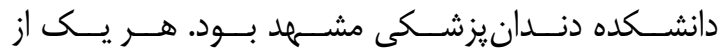
شركت كنندكان كه در حين تحقيق قادر به ادامه همكارى نبود، نمره دانش (نمره ييش آزمون) براساس جدول شماره

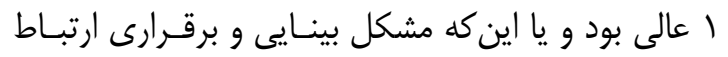

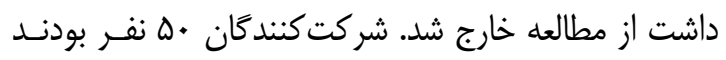

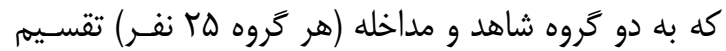

در اين مطالعه كتابجهه آموزشـى و يرسـشنامـهاي در

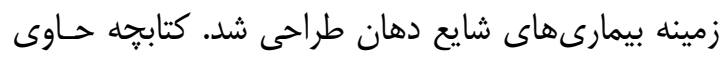
مطالبى در مورد بيمارى هاى شـايع حفـره دهـان شـامل؛ زئل

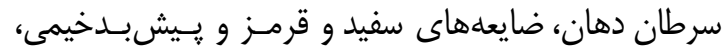

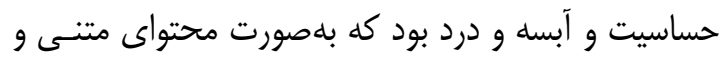

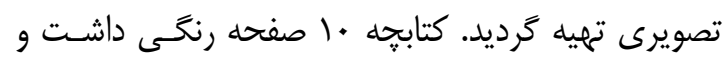

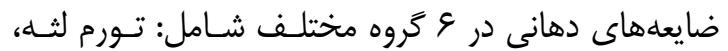
تورم بافتى، سفيدى در دهان، لكههاى رنكى، زخم دهانى

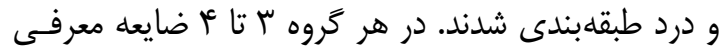

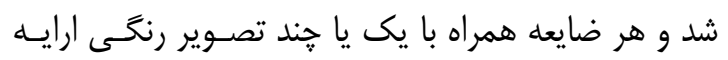

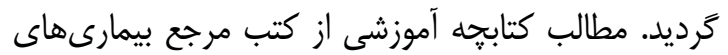

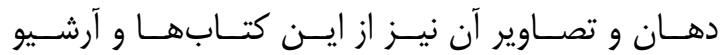

دهانى بسيار بالاست. از طرف ديگر سطح دانش در زمينه بيمارىهاى دهانى بسيار يايين است و حتى برخى بيماران

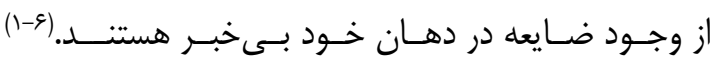

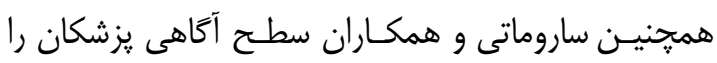

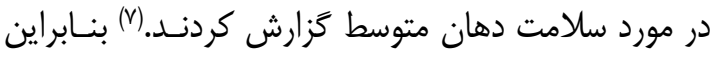

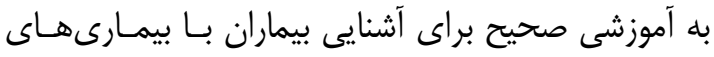

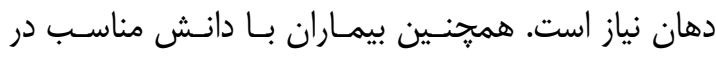

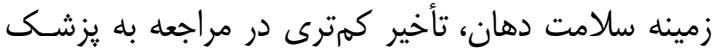

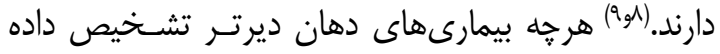

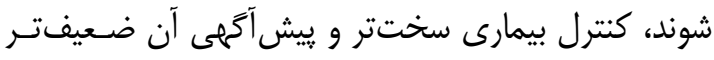

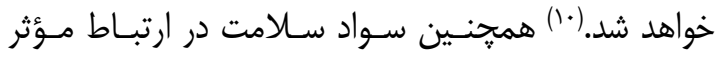

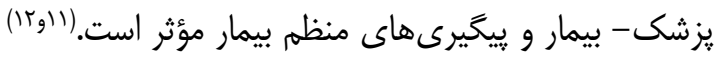

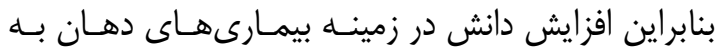
تشخيص بلموقع و كنترل بهتر بيمارى نيز كمى خواهــد

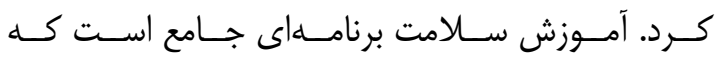

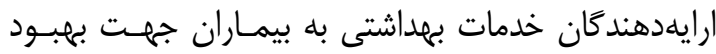

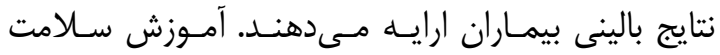

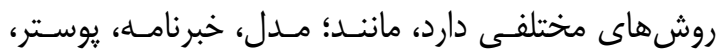

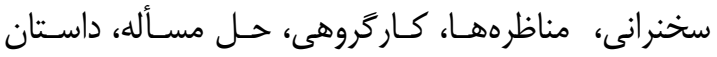

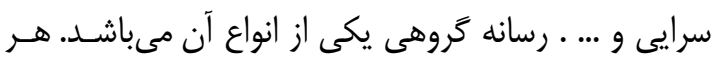

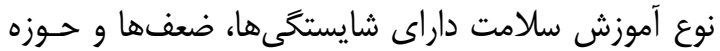

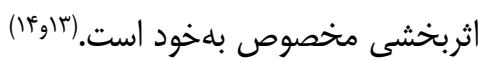

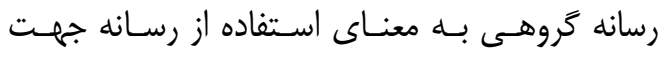

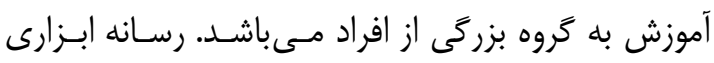

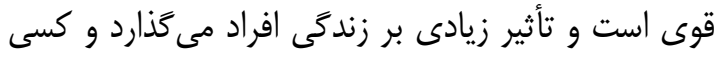

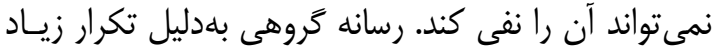

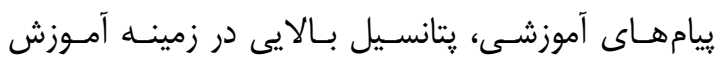

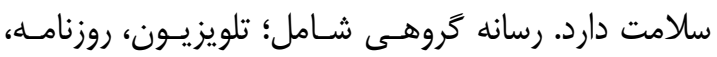
مجله، بمفلت، بيلبورد و راديو است. يكسى از شـكلهـائ

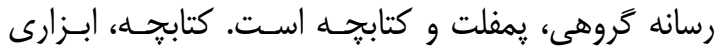

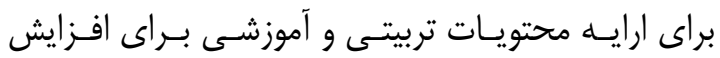

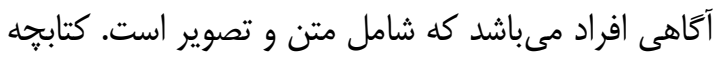
بلخاطر انتشار وسيع بسيار مورد توجه قرار گرفته و كاربرد كَسترداى دارد و در مقايسه با يوستر اطلاعات بيشترى لهرى 


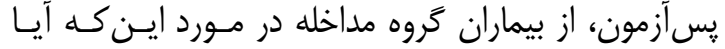

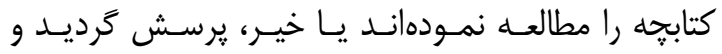

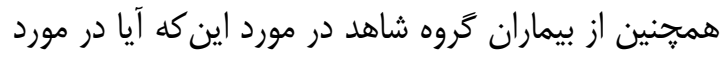

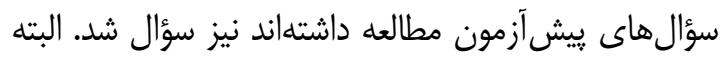

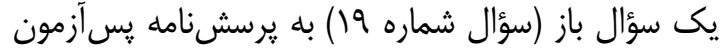
بهعنوان شاخص افزايش دانـش اضـافه شــــ ايـن سـؤال

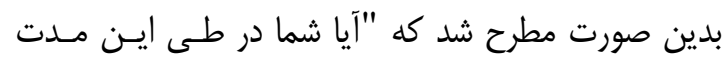
بيمارى دهانى خاصى را در خود يا اطرافيانتان كه تـاكنون

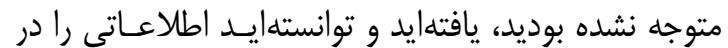

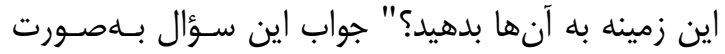

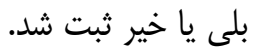

براى بيان توزيع اطلاعات جمعيتشـناختى و مقايسـهـ نمره يِيش آزمون از آزمونهاى كاى اسكوئر، مـنـويتنى و و

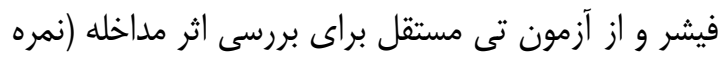

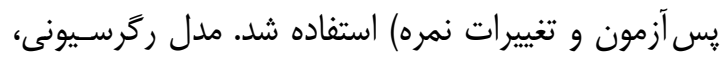

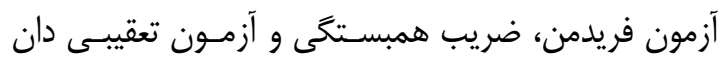

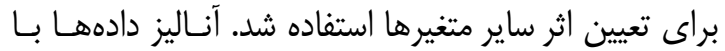
استفاده از نرمافزار بץ SPSS انجام شد. سطح معنسى دارى كمتر از ه./ در نظر كرفته شد.

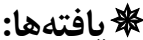

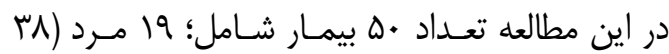

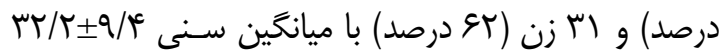

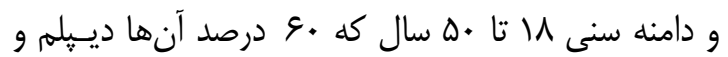

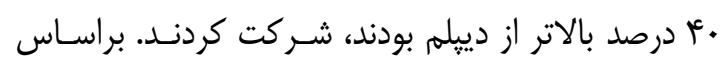

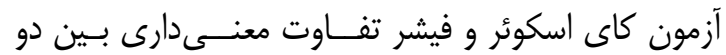
كروه مداخله و شاهد از نظر جنسيت و ميـزان تحصـيلات وجـود نداشت (P=•/DVE ، P=•/VVI) كمترين و بيشترين نمره ييش آزمون در كروه مداخله

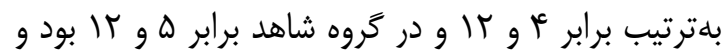

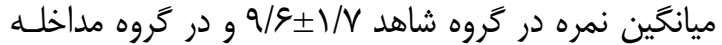

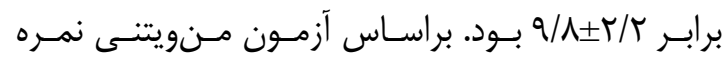

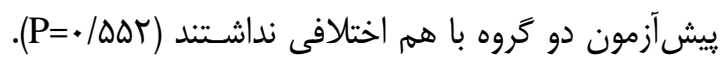

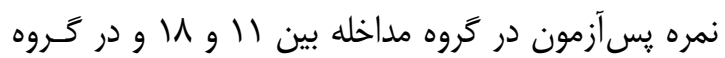

فوتـوكر افى هـاى بخـش بيمـارى هــاى دهـان دانشـكـده

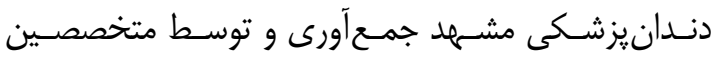

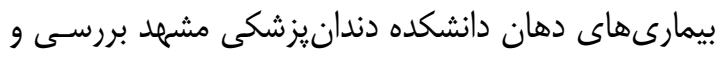

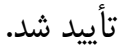

يرسشنامه طراحى شده، دو قسمت داشت. در قسمت اول، اطلاعات جمعيتشــاختى افـراد شـركت كنتـــه و در

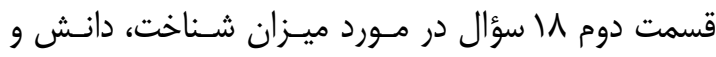

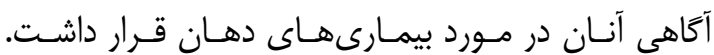

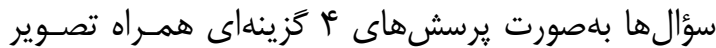

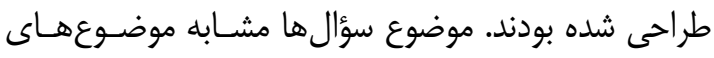

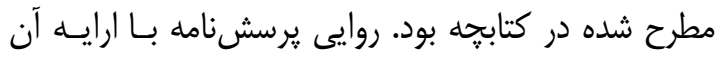

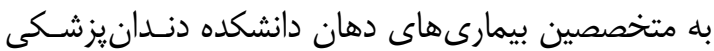
مشهر و انعكاس نظرهاى آنها تعيين و مشكلات موجـود يس از اعمال نظرهاى آنها رفع شد. بايايى آن نيز با ارايه

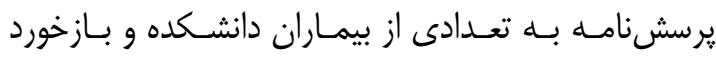

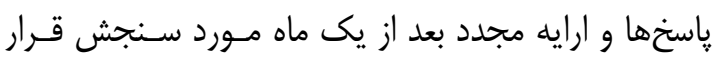

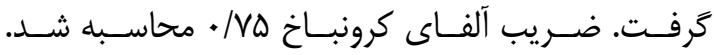
يرسش نامه در دو مرحله قبل و بعد از مداخلـه بــه عنــوان

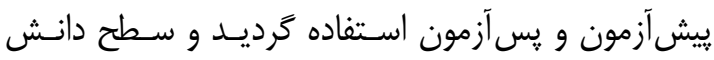
آنها با توجه به تعداد ياسخ هاى صحيح إنه (هر ياسخ صحيح يك نمره) نمر هدهى شد (جدول شماره ().

\section{جدول ( - نمرهدهى سطح دانش}

\begin{tabular}{|c|c|}
\hline سطح نمره & سطح دانش \\
\hline 11-10 ( بيشتر از ها و كمتر، مساوى با 1) & عالى \\
\hline ها - זו (بيشتر از זוو كمتر، مساوى با ه1) & خوب \\
\hline rا-A (بيشتر از ^و كهتر، مساوى با rI) & متوسط \\
\hline (كمتر، مساوى با A) & ضعيف \\
\hline
\end{tabular}

به هر دو گروه يرسش نامه يِيش آزمون داده شد و نمره

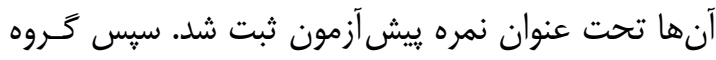

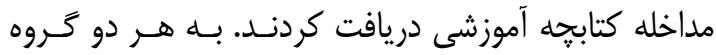

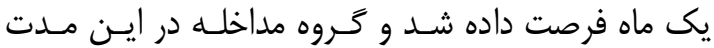

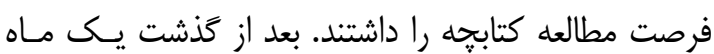

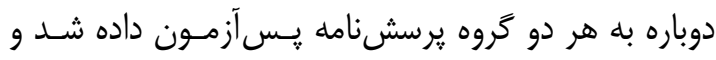

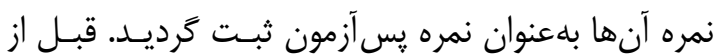




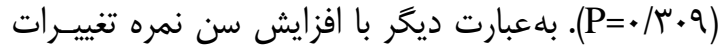
به مقدار كمى افزايش يافت. اختلاف نمرههاى حيطههاى

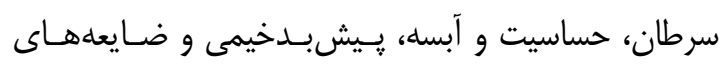

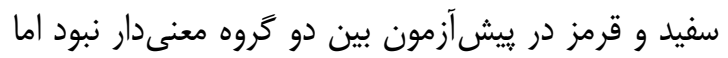
مقدار نمره حيطـه درد مربـوط بـهـ هـيشآزمـون در كـروه مداخله براساس آزمون منويتنى بهطور معنىدارى بيشتر

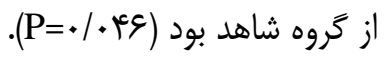
بلهعبارت ديخر كروه مداخلـه هـيش از انجـام مداخلـهـ

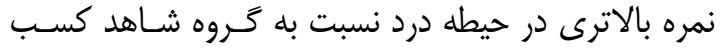

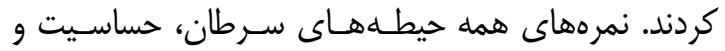

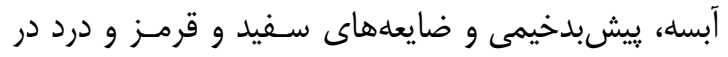

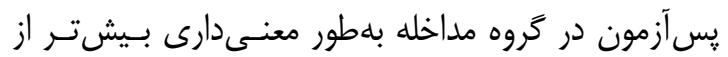

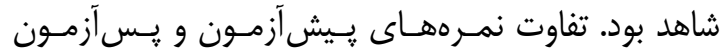

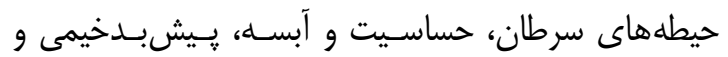

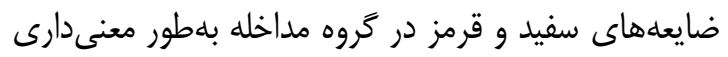

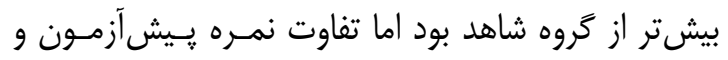

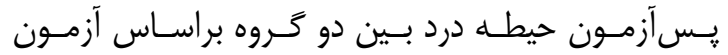

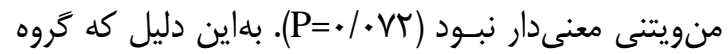

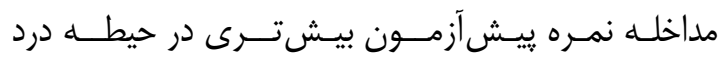

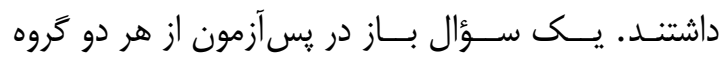

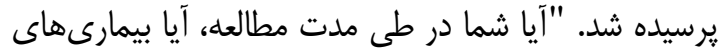

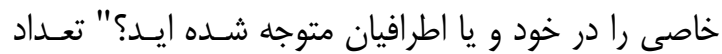

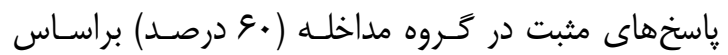

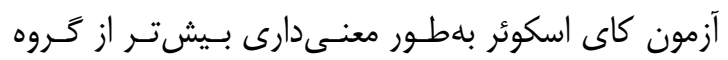

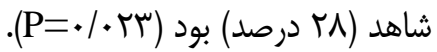

شاهد بين ه و سا بود. ميانخين نمره يسآزمون در خـروه شاهد 9/V و در كروه مداخله برابر آما و و براساس آزمون

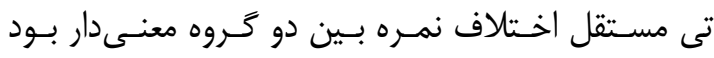

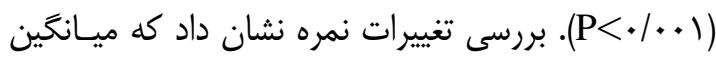
تغييرات نمره در كروه شاهد ب/ /• و در كروه مداخله برابـر

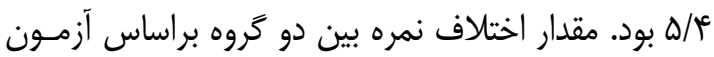

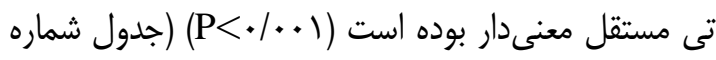

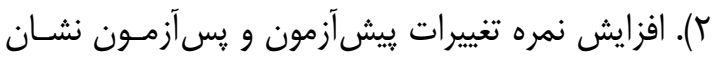
داد، كتابجه توانسته باعث افـزايش دانـش گَـروه مداخلـه

طبق نتايج مطالعه، مشاهده مى گردد كه هم در مردان

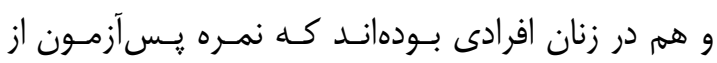
ييش آزمون آنها كمتر شده است، اما متوسط نمره تغييرات

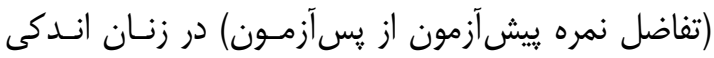

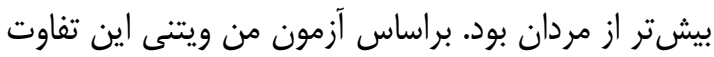

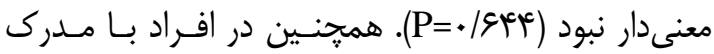

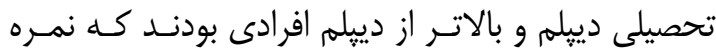

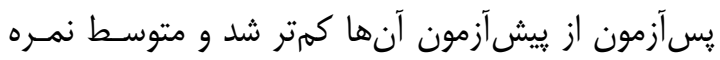

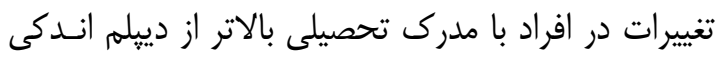

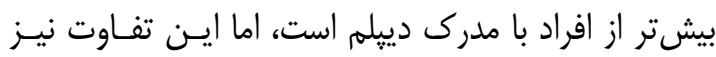

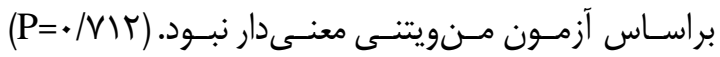

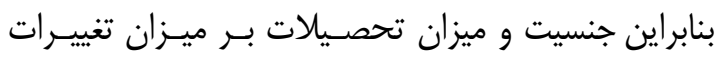

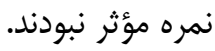

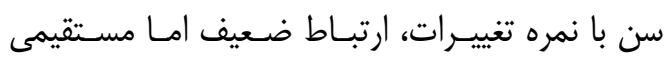
داشـت ولى مقـــار ضريسب همبستخـى معنى دار نبــود

جدول r - مقايسه نمرههاى بيشآزمون، بس آزمون و تغييرات آن در آزمون تى مستقل در دو تروه مورد مطالعه

\begin{tabular}{|c|c|c|c|c|c|c|c|}
\hline \multicolumn{2}{|c|}{ تغييرات نمره } & \multicolumn{2}{|c|}{ مقايسه نمره بِ آزمون } & \multicolumn{2}{|c|}{ مقايسه نمره ييش آزمون } & \multirow{2}{*}{ تعداد } & \multirow{2}{*}{ 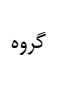 } \\
\hline دامنه تغييرات & انحراف معيار ذميانكين & دامنه تغييرات & انحراف معيار ثيانكين & دامنه تغييرات & انحراف معياريدميانكين & & \\
\hline با تاج & $\Delta / \tau \pm 1 / \Delta$ & لا & $10 / r \pm 1 / 8$ & F تاك & $q / \Lambda \pm r / r$ & ro & مداخله \\
\hline 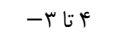 & $1 / 9 \pm . / T$ & هـ تا سו & $9 / v \pm 1 / \wedge$ & هـ تا YI & $q / 9 \pm 1 / V$ & $r \Delta$ & شاهد \\
\hline \multicolumn{2}{|c|}{$\mathrm{P}<\cdot / \cdot .1^{*}$} & \multicolumn{2}{|c|}{$\mathrm{P}<\cdot / \cdot.)^{*}$} & \multicolumn{2}{|c|}{$\mathrm{P}=\cdot / \Delta T Y$} & \multicolumn{2}{|c|}{ نتيجه آزمون } \\
\hline
\end{tabular}

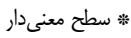




\section{بحث و نتيجه كيرى:}

راهنمـا بـود. مطالعـه يتـى نيـز بــهــــورت مشـابهى از

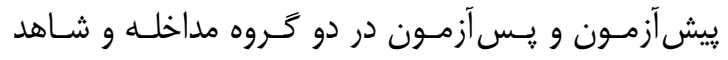

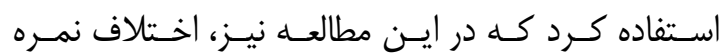
ييشآزمون در دو كروه قبل از انجام مداخله معنىدار نبـود

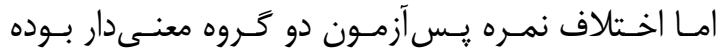

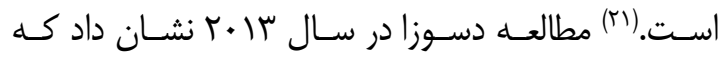
ميانگين تغييرات دانايى درباره سرطان دهان در افراد كروه مداخله بالاتر از كروه شاهد در تمـام مــدت مطالعـه بـوده

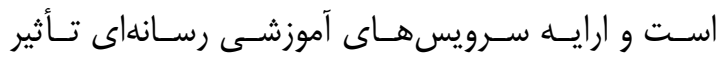

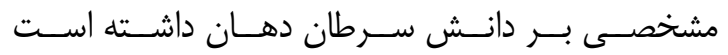

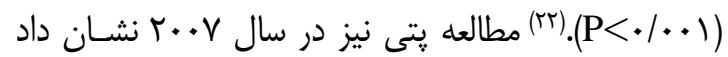

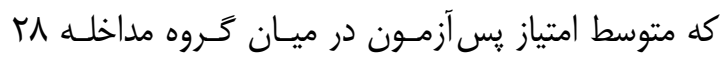

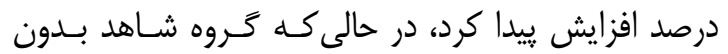

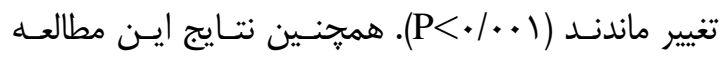
نشان داد كه تنها متغيرى كه در تغييرات دانش مؤثر بـود،

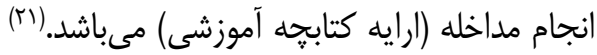
سن، جنس و ميزان تحصيلات بـشـى بـر دانش و

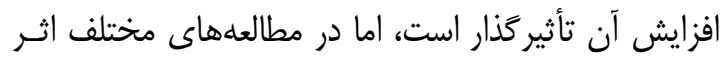

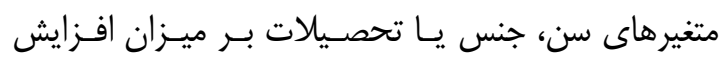

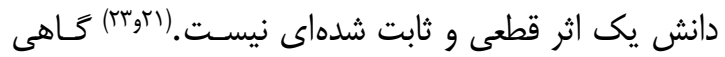
افراد با تحصيلات بالا، دانش زيادى نسبت به بيمارى نهاى دهان ندارند كه عوامل مختلفى مانند؛ شرايط اجتماعى و

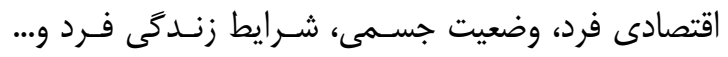

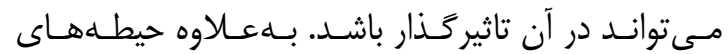
تحصيلاتى افراد متفاوت است، بنابراين بالاتر بودن مقطع

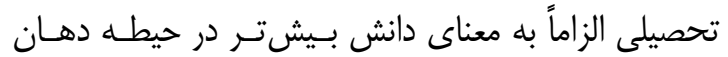

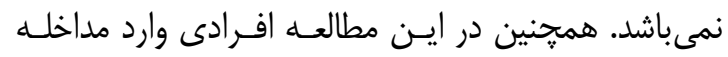
شدند كه از ابتدا دانش كمى در زمينه بيمارىهـاى دهـ دهـان داشتند، بنابراين سطح بالاى تحصيلات، دانش آنها را در درئل زمينه بيمارىهاى دهان بالا نبرده بود. در اين مطالعه، رابطه سن با افزايش ميزان دانش دئل نسبتاً

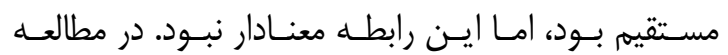

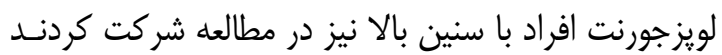

در اين مطالعه ^ץ درصد از افراد شركت كننده مرد و بك

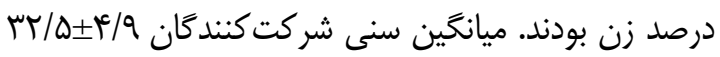

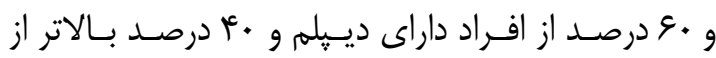

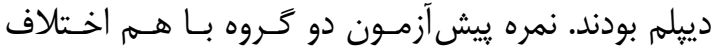

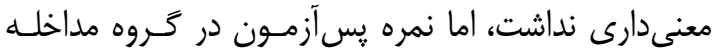

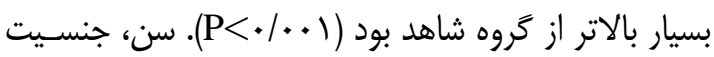

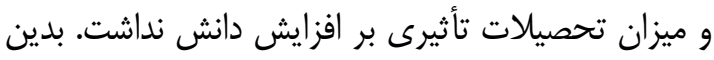
ترتيب تنها متغير مؤثر بر افـزايش دانـش، ارايـهـ كتابهـــهـ

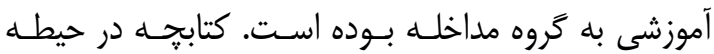

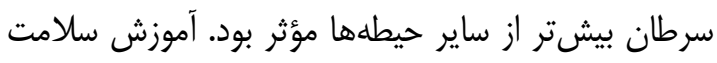

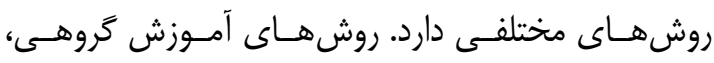

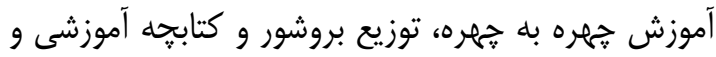

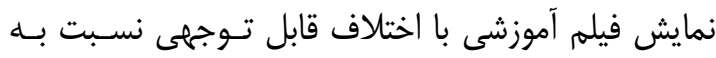

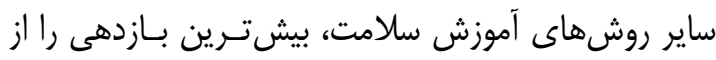

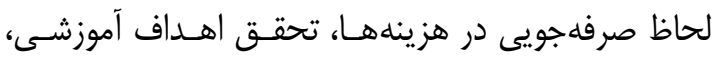
دسترسى گروههاى هدف، مقبوليت مردمى و قابليت اجـرا

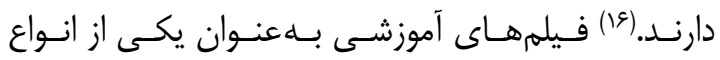

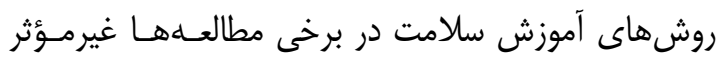

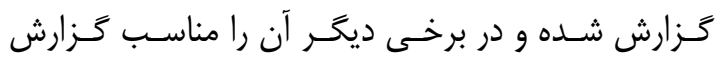

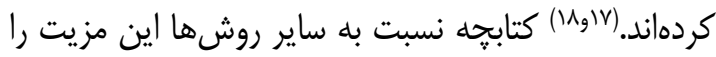
دارد كه علاوه بر افراد شركت كننده در مداخله، اطرافيان و

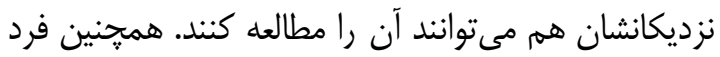

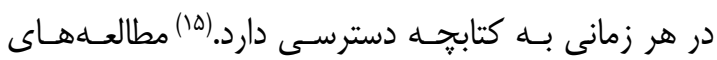

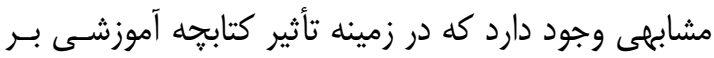
افزايش دانش بيمارى سرطان دهان و بيمارىهاى مهمر و

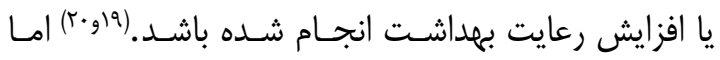

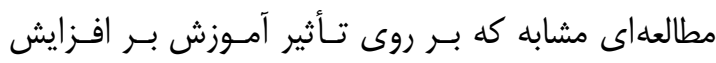
دانش در زمينه بيمارىهاى مختلف و شايع دهـان انجـام

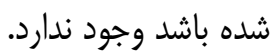
نمره افراد گروه مداخله و شاهد در ييشآز مآزون تفـاوت

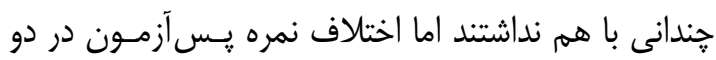

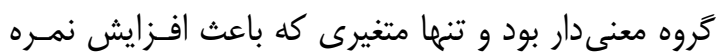

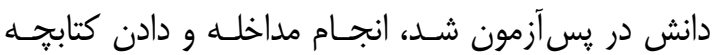


افراد را نسبت به بيمارىهاى دهان بهبود بخشد. جمنى و

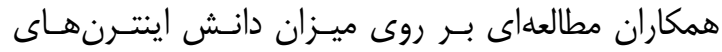
يزشكى در زمينه بيمارىهاى دهان انجام و نشـان دادنـد، دئس

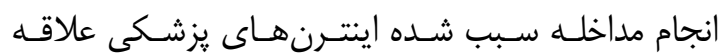

بيشترى به كسب اطلاعات در اين زمينه ييدا كنند.(هان در اين مطالعه حجم نمونه كوجى بود، بنابراين بعضى بلى از نتايج ممكن است با مطالعههاى مشابه با حجـم نمونسه

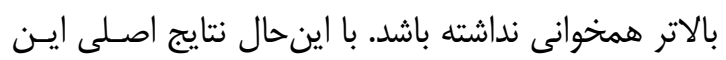
مطالعه مشابه مطالعهاى ديخــر محققين بـود. ييشـنهاد

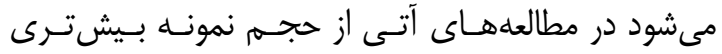

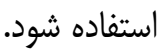
در اين مطالعه افزايش نمره يسآزمون و تغييرات نمره شاخصى براى افزايش دانش فرد در نظر كرفته شد. استفاده از شاخصهايى جـون؛ ميـزان رعايـت بهداشـت، مراجعـهـ

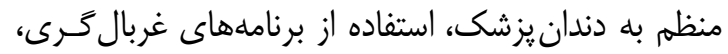

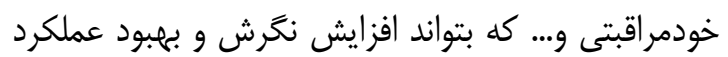
را نشان دهد در مطالعههاى بعدى توصيه مىشـود. ارايـهـ كتابجه رنكى متنى - تصويرى مىتواند راهكارى مناسب و

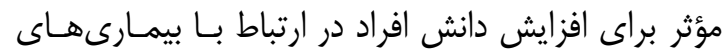

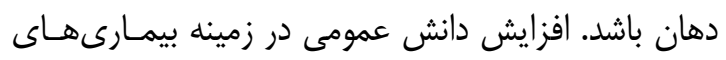

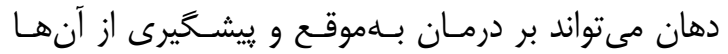

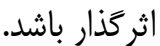

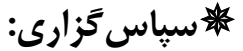

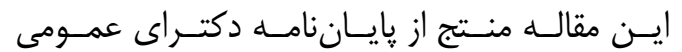

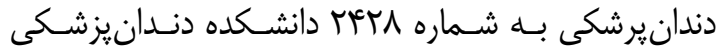

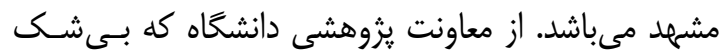

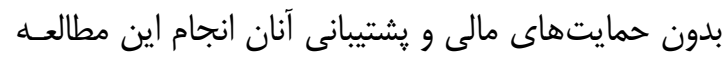

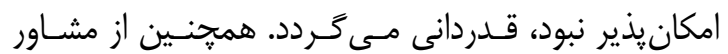
محترم آمار، آقاى جوان كه در انجام اين مطالعه همكارى

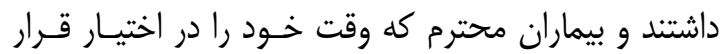

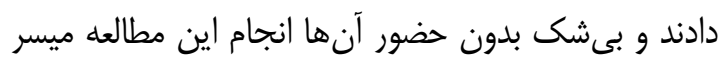

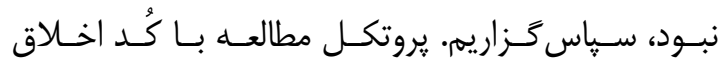
IR.mums.Sd.REC. 1394.51 به تأييد رسيد.
بهمين دليل سن و ميزان دانش در مطالعـه وى رابطـهـ

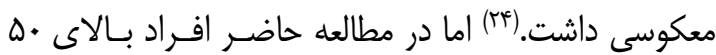

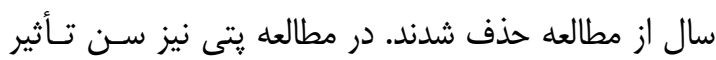

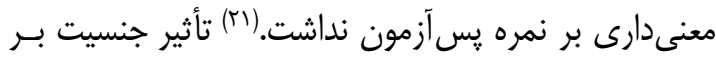
ميزان دانش در مطالعههاى مختلف نيز متفـاوت كَزارش

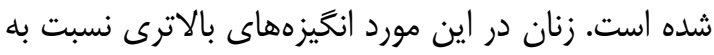

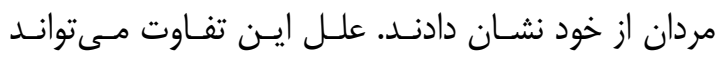

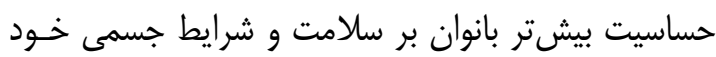
و دايره اطلاعاتى وسيعتر مردان باشد. در مطالعـه حاضـر متوسط دانش و تغييرات دانش در زنان اندكى بالاتر بـود.

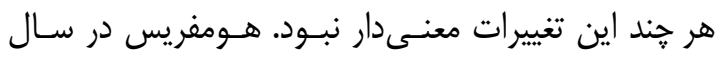

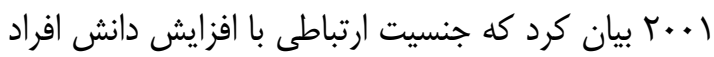

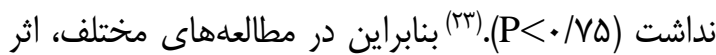
متغيرهاى زمينهاى مربوط به اطلاعات دموكر افيك افـراد بلهورت متفاوتى ذكر شده است كه تقريباً مشابه بـا ايـن

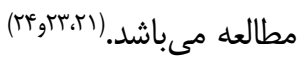
در اين مطالعه سؤالهاى يرسشنامه به عأ حيطه تقسيم

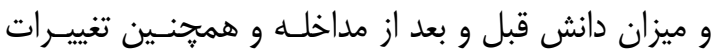

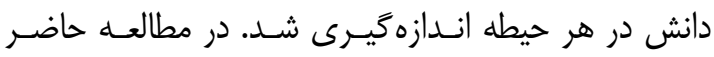

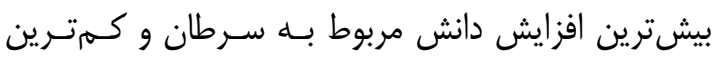
مربوط به درد بود. هومفريس در مطالعهاى علايم سرطان

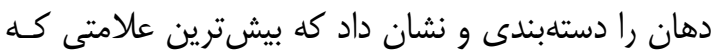
بلنظر شركت كنند

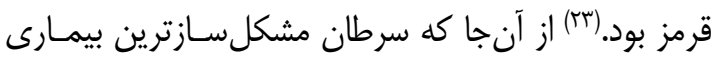

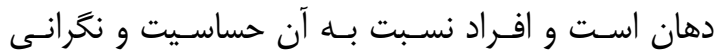
بيشترى دارند، شايد بتوان كفت، بيماران مطالب كتابجـهـ در زمينه سرطان دهان را بهتر مطالعه كردهاند.

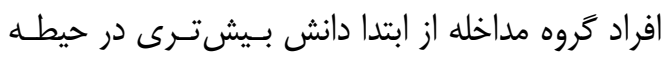

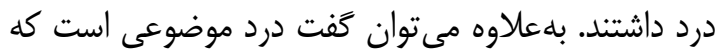

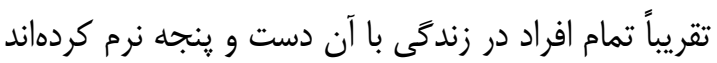

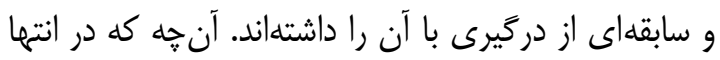

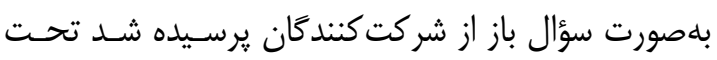

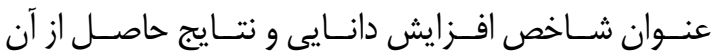

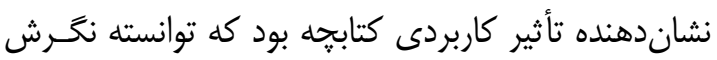


1. Jin LJ, Lamster IB, Greenspan JS, Pitts NB, Scully C, Warnakulasuriya S. Global burden of oral diseases: emerging concepts, management and interplay with systemic health. Oral Dis 2016; 22(7): 609-19. doi: 10. 1111/odi.12428.

2. Mozafari PM, Dalirsani Z, Delavarian Z, Amirchaghmaghi M, Shakeri MT, Esfandyari A, et al. Prevalence of oral mucosal lesions in institutionalized elderly people in Mashhad, Northeast Iran. Gerodontology 2012; 29(2): e930-4. doi: 10.1111/j.1741-2358.2011. 00588.x.

3. Ali M, Joseph B, Sundaram D. Prevalence of oral mucosal lesions in patients of the Kuwait University Dental Center. Saudi Dent J 2013; 25(3): 111-8. doi: 10.1016/j.sdentj. 2013.05.003.

4. Cadugo MA, Chua MG, Feliciano MA, Jimenez FC Jr, Uy HG. A preliminary clinical study on the oral lesions among the Dumagats. J Philipp Dent Assoc 1998; 50(2): 36-42.

5. Campisi G, Margiotta V. Oral mucosal lesions and risk habits among men in an Italian study population. J Oral Pathol Med 2002; 31(8): 504. doi: 10.1034/j.1600-0714. 2001.300104.x.

6. Delavarian Z, Zavar S. Prevalence of oral lesions and awareness of their presence in patients attending to Oral-Medicine Center of Mashhad Dental School. J Dent Sch Shahid Beheshti Univ Med Sci 2004; 22(3): 425-36. [In Persian]

7. Sarumathi T, Saravanakumar B, Datta M, Nagarathnam T. Awareness and knowledge of common oral diseases among primary care physicians. J Clin Diagn Res 2013; 7(4): 76871. doi: 10.7860/JCDR/2013/5419.2908.

8. Jamieson LM, Armfield JM, Roberts-

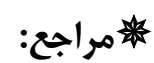

Thomson KF. Oral health inequalities among indigenous and nonindigenous children in the Northern Territory of Australia. Community Dent Oral Epidemiol 2006; 34(4): 267-76. doi: 10.1111/j.1600-0528.2006.00277.x. 9. Scott TL, Gazmararian JA, Williams MV, Baker DW. Health literacy and preventive health care use among Medicare enrollees in a managed care organization. Med Care 2002; 40(5): 395-404.

10. Sarabadani J, Pakfetrat A, Delavarian Z, EbrahimiNik Z, Nejat A, KamelBoron A. Knowledge and diagnostic skill of general dentist in Khorasan Razavi province (Iran) toward oral common diseases 2009-10. J Mashad Dent Sch 2012; 36(2): 113-20. [In Persian]

11. Beck RS, Daughtridge R, Sloane PD. Physician-patient communication in the primary care office: a systematic review. J Am Board Fam Pract 2002; 15(1): 25-38.

12. Selden C, Zorn M, Ratzan S, Parker R. Health Literacy. Bethesda: National Library of Medicine; February 2000. 2000-1.

13. Liu XL, Shi Y, Willis K, Wu CJ, Johnson M. Health education for patients with acute coronary syndrome and type 2 diabetes mellitus: an umbrella review of systematic reviews and meta-analyses. BMJ Open 2017; 7(10): e016857. doi: 10.1136/bmjopen-2017016857.

14. Yingklang $M$, Sengthong $C$, Haonon O, Dangtakot R, Pinlaor P, Sota C, et al. Effect of a health education program on reduction of pediculosis in school girls at Amphoe Muang, Khon Kaen Province, Thailand. PLoS One 2018; 13(6): e0198599. doi: 10.1371/journal.pone.0198599.

15. Koelen MA, van den Ban AW. Health education and health promotion. Wageningen, 
The Netherlands: Wageningen Academic Publishers; 2004.

16. Mehrolhassani MH, Jadidi R, Amini S. Prioritization of health education techniques in Markazi province health center through analytical hierarchy process and goal programming. Iran $\mathbf{J}$ Health Educ Health Promot 2016; 3(4): 328-39. [In Persian]

17. Ghorbani H. Comparison of conventional methods and educational films on microbial plaque reduction in elementary school students in Tehran. Central library of Shahid Beheshti Universsiy of Medical Scienses 2010. [In Persian]

18. Birang R, Shakerian K, Yazdanpanah Samani F, Nadimi M. The effect of education by visual media on oral health promotion of students. J Arak Univ Med Sci 2006; 9: 1-6. [In Persian]

19. Boundouki G, Humphris G, Field A. Knowledge of oral cancer, distress and screening intentions: longer term effects of a patient information leaflet. Patient Educ Couns 2004; 53(1): 71-7.

20. Scott SE, Khwaja M, Low EL, Weinman J, Grunfeld EA. A randomised controlled trial of a pilot intervention to encourage early presentation of oral cancer in high risk groups. Patient Educ Couns 2012; 88(2): 2418. doi: 10.1016/j.pec.2012.03.015.
21. Petti S, Scully C. Oral cancer knowledge and awareness: primary and secondary effects of an information leaflet. Oral Oncol 2007; 43(4): 408-15. doi: 10.1016/j.oraloncology. 2006.04.010.

22. D'Souza V, Blouin E, Zeitouni A, Muller K, Allison PJ. Do multimedia based information services increase knowledge and satisfaction in head and neck cancer patients? Oral oncol 2013; 49(9): 943-9. doi: 10.1016/ j.oraloncology.2013.06.005.

23. Humphris GM, Ireland RS, Field EA. Immediate knowledge increase from an oral cancer information leaflet in patients attending a primary health care facility: a randomised controlled trial. Oral Oncol 2001; 37(1): 99-102. doi: 10.1016/S1368-8375(00) 00069-5.

24. López-Jornet $\mathrm{P}$, Camacho-Alonso F, Miñano FM, Sanchez-Siles M. Evaluation of the different strategies to oral cancer knowledge: a randomized controlled study. Psychooncology 2013; 22(7): 1618-23. doi: 10.1002/pon.3189.

25. Chamani G, Zarei M, Nemati H. Study of the level of awareness \& diagnostic skills of medical interns regarding common oral diseases and their manifestations at the medical colleges of Kerman and Zahedan. J Shahid Sadoughi Univ Med Sci 2003; 11(2): 59-1. [In Persian] 